\title{
INSUFICIENCIAS DEL ANÁLISIS ECONÓMICO COMO BASE PARA UNA TEORÍA DE LA ADJUDICACIÓN ${ }^{1}$
}

\author{
INSUFFICIENCIES OF ECONOMIC ANALYSIS AS A BASIS FOR A \\ THEORY OF ADJUDICATION
}

\section{Carlos Diego Martínez Cinca ${ }^{2}$}

\begin{abstract}
RESUMEN: El presente trabajo analiza las insuficiencias que le impedirían al movimiento conocido como Análisis Económico del Derecho -liderado durante treinta años por el Juez Richard Posner- sentar las bases de una teoría de las decisiones judiciales o teoría de la adjudicación.
\end{abstract}

Palabras clave: Análisis Económico del Derecho, adjudicación, formalismo jurídico, Richard Posner, Neil MacCormick.

ABSTRACT: This paper analyses the theoretical insufficiencies that would prevent the Law and Economics movement -leaded by Judge Richard Posner for more than thirty yearsfrom setting up the basis for a theory of adjudication.

Key words: Law and Economics, adjudication, legal formalism, Richard Posner, Neil MacCormick.

\section{OBJETIVOS DEL PRESENTE TRABAJO}

El presente trabajo pretende analizar las causas que le impedirían al movimiento del Law and Economics, también conocido como Análisis Económico del Derecho (AED en adelante), sentar las bases de una teoría plausible de la adjudicación jurídica (o teoría de las decisiones judiciales), tal como Dworkin la define en su obra Los derechos en serio.

Tras un breve estado de la cuestión que introduzco en primer lugar y que de manera sucinta pretende graficar la situación actual del AED en el ámbito de la Legal Theory anglosajona para quienes no se encuentren familiarizados con ella, en el primer núcleo teórico de este trabajo me concentraré en un aspecto de gran interés para el avance de la jurisprudencia: la pretensión de anticipar, prever o calcular las consecuencias de las sentencias judiciales en el "mundo real". A tal efecto, analizaré los obstáculos teóricos que, conforme a esa pretensión, le impedirían al AED sentar las bases de una teoría de las decisiones judiciales (teoría de la adjudicación) que sea coherente en sus formulaciones y que pueda ofrecer, a la vez, una respuesta satisfactoria a lo que hoy constituye un desafío para esta crucial dimensión de la teoría general del Derecho. En efecto, uno de los problemas más relevantes para

\footnotetext{
1 El presente trabajo es resultado de las investigaciones realizadas en el marco del Proyecto FONDECYT Posdoctorado 3120252: "Insuficiencias del Análisis Económico del Derecho frente a los casos difíciles. Claves para la superación del pragmatismo consecuencialista de Richard Posner desde el horizonte de los bienes humanos básicos de John Finnis".

2 Instituto de Filosofía de la Universidad de los Andes. Correo electrónico: cdmartinez@miuandes.cl.
} 
una teoría de la adjudicación, tal como la entienden hoy los principales exponentes de la filosofía del Derecho (Joseph Raz ${ }^{3}$, Ronald Dworkin ${ }^{4}$, Neil MacCormick ${ }^{5}$, John Finnis ${ }^{6}$, Robert $\mathrm{Alexy}^{7}$, entre otros) reside en la cuestión de cómo resuelven los jueces (o deberían resolver) los llamados “casos difíciles”, es decir, aquellos casos en los que la lógica deductiva propia del formalismo jurídico no parece constituir una herramienta suficiente para arribar a conclusiones coherentes y consistentes con las reglas de Derecho establecidas ${ }^{8}$. En ese sentido, la posibilidad de calcular o anticipar las consecuencias de las sentencias judiciales en el "mundo real" parece guardar una estrecha relación con el problema de los "casos difíciles” pues se presenta, a priori, como un principio de solución a esa cuestión. Mi análisis procurará poner de manifiesto, sin embargo, algunos de los obstáculos teóricos que el AED enfrenta como base para una teoría de la adjudicación, y de manera indirecta procurará también señalar si la solución al problema de los "casos difíciles" debe encaminarse al cálculo de las consecuencias que las sentencias judiciales acarrean en el "mundo real" u orientarse más bien según otra dirección.

\section{BREVE ESTADO DE LA CUESTIÓN}

En Los derechos en serio Ronald Dworkin sostiene que una teoría general del Derecho debería poder dar algún tipo de respuesta coherente a por lo menos tres de las principales preguntas que cualquier observador del fenómeno jurídico podría formular: 1) cómo se establecen y se reconocen las normas de carácter general (leyes, por ejemplo) que un determinado grupo humano o sociedad acatará como obligatorias; 2) cómo determinados funcionarios encargados de impartir justicia dirimen (o deberían dirimir) los conflictos surgidos entre los distintos integrantes de aquella sociedad en función de las conductas establecidas como obligatorias por normas de carácter general; y 3) por qué y cómo los integrantes de dicha sociedad acatan (o deberían acatar) las normas generales establecidas como obligatorias y las sentencias emanadas de los funcionarios encargados de impartir justicia. Como puede apreciarse, entonces, existirían al menos tres aspectos o dimensiones particulares que una teoría general del Derecho debería poder integrar satisfactoriamente: una teoría de la legislación, una teoría de la adjudicación y una teoría de la obediencia civil u obediencia al Derecho?.

\footnotetext{
${ }^{3}$ Raz (2009) pp. 223 y ss.

${ }^{4}$ Dworkin (2002) pp. 146-208.

${ }^{5}$ Maccormick (1997) pp. 100-151.

${ }^{6}$ Finnis (2011b) pp. 399-400.

AleXy (1993) pp. 157-172.
}

${ }^{8}$ Según Manuel Atienza, en la concepción de MacCormick, los "casos difíciles" serían aquellos que presentan problemas de "interpretación" o de "relevancia" en relación con la premisa normativa, o bien de "prueba" o "calificación" en relación con la premisa fáctica ATIENZA (2005) p. 112. Sin embargo, la línea divisoria entre "casos fáciles" y "casos difíciles" no es tan clara, como reconoce el propio MAсCоRмicK (1997) p. 197.

9 Dworkin (2002) pp. 32 y ss. La teoría de la legislación o de las normas generales fue el foco central del normativismo o positivismo jurídico en los años sesenta: véase HART (1998) pp. 33-61 y 99-123. Las dos últimas dimensiones de la teoría general han sido las más exploradas en los últimos veinticinco años "post-positivistas" 
Ahora bien, en los últimos 50 años de la Legal Theory norteamericana se ha desarrollado un intento por construir una teoría general del Derecho a partir de los postulados centrales de la economía neoclásica, particularmente a partir de los postulados en torno a la conducta racional de los individuos, a la eficiencia como pauta normativa, y a las normas como incentivos para la conducta eficiente de los individuos. Dicho intento corresponde al movimiento conocido como Law and Economics o "nuevo análisis económico del Derecho" ${ }^{10}$, surgido a inicios de 1960 a partir de una serie de estudios pioneros como los de Ronald Coase, Guido Calabresi y Armen Alchian ${ }^{11}$, que recibieron una calurosa acogida en los programas de investigación y docencia de la Universidad de Chicago (y posteriormente de otras universidades norteamericanas y centros de estudios). La historia intelectual de este movimiento, sus orígenes y fundamentos filosóficos, sus aspiraciones políticas y hasta sus supuestas vinculaciones ideológicas han sido largamente estudiados y analizados, a punto tal que existe, al presente, una bibliografía especializada de considerables proporciones por medio de la cual es posible conocer los detalles de su historia intelectual y de su evolución doctrinaria ${ }^{12}$.

Sin embargo, luego de 50 años de esfuerzos teóricos recogidos en innumerables trabajos científicos de excelente rigor y calidad académica, el AED parece no haber podido integrar los numerosos campos de estudios y los datos de sus investigaciones en una teoría general del Derecho en el sentido definido por Dworkin. En efecto, uno de sus mayores obstáculos parece residir en la dificultad para elaborar una teoría coherente y plausible de la adjudicación jurídica (o de las decisiones judiciales) a punto tal que esa dificultad ya no parece proceder del estado embrionario en que la teoría se hallaría -y por consiguiente el logro de su madurez epistemológica tampoco sería una cuestión de tiempo, como afirmaba Richard Posner en los setenta y en los ochenta ${ }^{13}$ - sino en las contradicciones que acarrearía la maximización de la riqueza como pauta de asignación de derechos. En términos más simples podría decirse que el AED ha logrado reunir una enorme cantidad de datos que todavía esperan por una teoría de la adjudicación que los contenga y los ordene.

Se han llevado a cabo investigaciones, incluso, que han aportado las evidencias empíricas necesarias para discutir si el AED se encuentra aún vigente o bien ha entrado en una fase de declinación intelectual. Algunas de esas evidencias empíricas han sido recogidas, por ejemplo, en un trabajo que presenta al AED como un fenómeno intelectual típicamente

de la filosofía del Derecho. El debate Raz-Finnis en el ámbito de la filosofía anglosajona es un ejemplo de ello: véase Dickson (2006) pp. 1-36.

${ }^{10}$ La expresión "nuevo" análisis económico del Derecho fue empleada por Posner a comienzos de los setenta para diferenciarse del "viejo" análisis económico desarrollado por John Commons y los institucionalistas norteamericanos en la década de los treinta; véase POSNER (1975) pp. 758 y ss.

${ }^{11}$ Coase (1960) pp. 1-44; Calabresi (1961) pp. 499-553; Alchian (1965) pp. 816-829.

12 Dada la abundancia de fuentes existentes al respecto, es recomendable comenzar por una obra introductoria, de carácter crítico-exploratorio, dotada de un indudable rigor científico y comprensiva de las diversas corrientes y orientaciones del movimiento, como es el ya clásico estudio de MerCado Pacheco (1994). Un estudio igualmente serio, bien documentado y más breve, es el de MACKAAY (2000). Una visión algo más comprometida con los desarrollos laterales del movimiento es la de Mercuro y Medema (2006). La perspectiva interna de los propios fundadores y exponentes del movimiento se recoge en PARISI y ROWLEY (2005).

13 Posner (1975) p. 779; Posner (1987) p. 773. 
norteamericano que tendría ciertas dificultades para echar raíces fuera de la jurisprudencia de aquel país, ya que incluso no habría logrado arraigarse efectivamente en ella a pesar de las características propias del Common Law que deberían haber favorecido su desarrollo como ningún otro sistema jurídico ${ }^{14}$. El autor de ese estudio pretende haber mostrado -con evidencias en la mano- que el campo del AED se limitaría a una minoría de académicos pertenecientes a un reducido número de escuelas de Derecho norteamericanas, bastante prestigiosas por cierto. Sin embargo el análisis y la ponderación de estas evidencias no constituyen el objeto central de mi trabajo, pues aquí solo pretendo analizar las dificultades que esta nueva jurisprudencia enfrenta al momento de ser aplicada por los jueces. Tales dificultades se hallarían emparentadas, hasta cierto punto, con las que desde antaño han afectado al "realismo jurídico" norteamericano, de cuyo enfoque teórico el AED sería de algún modo heredero, según la mirada de algunos autores ${ }^{15}$.

La necesidad de centrarse en un enfoque teórico de la cuestión antes que en un mero análisis cuantitativo es simple. Si bien el análisis de los datos comparativos que muestran el grado de impacto que el AED ha tenido en la jurisprudencia de los tribunales norteamericanos podría hacerse valer como un argumento más en torno a su viabilidad como posible teoría de la adjudicación, la cuestión del crecimiento o de la declinación del AED como jurisprudencia efectiva es más bien secundaria, ya que al plantear la discusión en esos términos se termina cayendo en la típica cuestión de "si el recipiente está medio lleno o medio vacío" (incluso a pesar de los datos que permitirían señalar que "el recipiente está vacío fuera de los Estados Unidos de Norteamérica" ${ }^{16}$ ). Planteada la discusión en esos términos, nos encontramos con el problema de que los datos no siempre arrojan conclusiones contundentes, no al menos en este campo en donde es difícil saber, por la naturaleza misma de la argumentación jurídica, si un juez ha tomado efectivamente en cuenta las contribuciones del AED o no, pues bien puede conocerlas y no necesariamente hacer referencias explícitas a ellas en sus sentencias. Tampoco contribuye sustancialmente a la discusión en torno a la viabilidad del AED como jurisprudencia efectiva el argumento basado en datos que parecen señalar que en América Latina el AED sería un campo de estudios periféricos todavía ignorado por las Cortes y los Tribunales de Justicia, y que su mayor recepción parecería haberse dado entre economistas interesados en el Derecho, abogados con algún título de posgrado en economía y asociaciones académicas interdisciplinarias interesadas en promover los estudios que relacionan la Economía y el Derecho (por ejemplo la Asociación Latinoamericana y del Caribe de Derecho y Economía, ALACDE) ${ }^{17}$. Resulta necesario, en efecto, un enfoque teórico de la discusión en torno a la viabilidad del AED como teoría de la adjudicación.

Pero el diagnóstico de las causas que explicarían las dificultades del AED para sentar las bases de una teoría de las decisiones judiciales ha sido hasta aquí insuficiente, al menos

14 Garoupa (2011) pp. 1517 y ss.

15 Véase Leiter (2011) pp. 95-96; Lynn SPencer (1998) pp. 26-62.

16 Garoupa (2011) p. 1518.

17 En Chile, al parecer, el AED ha estado lejos de ocupar un lugar relevante en la cultura jurídica: su desarrollo ha sido más bien pobre, como reconoce expresamente un académico ligado a la disciplina. Véase MerY NiETO (2004) pp. 138-139. 
en la formulación que han hecho aquellos académicos vinculados al AED e interesados en su difusión y aceptación vernácula. Por esa razón aquí me centraré en el análisis de las dificultades conceptuales que le impedirían al AED sentar las bases de una teoría de la adjudicación dejando expresamente de lado la discusión de si ha ganado terreno o no en el campo de la jurisprudencia real y efectiva. Las ventajas del enfoque conceptual sobre el enfoque empírico de la cuestión son claras: todo error de diagnóstico en materia de reforma judicial o incluso de planes de estudios encierra el peligro de orientar los recursos del Estado (o de las entidades privadas) hacia una dirección equivocada en la que los datos solo podrán comprobar un estado de cosas que pudo ser evitado mediante un diagnóstico previo. Por ello resulta imperioso analizar rigurosamente cuáles son las razones que le impedirían al AED sentar las bases para una teoría plausible de la adjudicación o de las decisiones judiciales.

En definitiva un análisis como el que aquí propongo aspira no solamente a discutir los fundamentos sobre los que se asienta una teoría que ha querido renovar la jurisprudencia en aras de una mayor cientificidad mediante la previsión de las consecuencias que las sentencias judiciales tendrían en el "mundo real", sino también mostrar, de manera tangencial, hasta qué punto en el Derecho es posible comprobar si una teoría es capaz de dar cuenta del "mundo real" o al menos explicarlo satisfactoriamente.

\section{DIFICULTADES DEL AED COMO BASE PARA UNA TEORÍA DE LAS DECISIONES JUDICIALES}

\subsection{UnA NUEVA "REVUelta CONTRA El FORMALISMO"}

Un académico chileno se lamentaba, hace algunos años, de que en Chile el AED haya estado "lejos de ocupar un lugar relevante en la cultura jurídica, cuya característica principal es su apego al formalismo y a un cierto fetichismo de la ley, donde la principal preocupación son los aspectos conceptuales de la norma jurídica, obviando la influencia del Derecho en la conducta de los individuos"18. Su diagnóstico del problema de la inoperancia y de la falta de asimilación del AED en la jurisprudencia y en la cultura jurídica de Chile hacía sencillamente responsables al formalismo jurídico y al fetichismo de la ley de aquella inoperatividad e indiferencia por los aspectos económicos del Derecho presentes en nuestra cultura jurídica.

Semejante diagnóstico -incompleto, a mi juicio- coincidía sustancialmente con el que Richard Posner formulara en uno de sus trabajos más incisivos publicados en la década de los ochenta, en el que casualmente hacía responsable al formalismo jurídico de todos los males que parecían aquejar al Derecho e impedir que se constituyese en una ciencia stricto sensu ${ }^{19}$. Para los analistas económicos del Derecho, la barrera más eficaz para impedir el ingreso del análisis económico en la ciencia jurídica parece haber sido, entonces, el formalismo jurídico. Pero ¿qué entienden generalmente los analistas económicos por formalismo jurídico?

\footnotetext{
18 Mery Nieto (2004) p. 138. Las negritas son mías.

19 Posner (1987) pp. 761-762.
} 
Richard Posner describe el formalismo jurídico norteamericano de Christopher Columbus Langdell -decano de la Facultad de Derecho de Harvard a fines del siglo XIXcomo una especie de "platonismo jurídico" autoconvencido de la existencia de un puñado de principios de Derecho eternos e inmutables corporeizados de manera imperfecta en las miles de opiniones doctrinarias publicadas" ${ }^{20}$. Para el formalismo, según Posner, la existencia de tales principios jurídicos inmutables se cristalizaría en la dogmática jurídica (otro nombre para el formalismo), que consistiría en una especie de reconstrucción inductivista de tales principios a partir de las sentencias y opiniones judiciales vertidas en los casos señeros [leading-cases] de la jurisprudencia. En la dirección opuesta, quienes deben argumentar a partir de tales principios (jueces o abogados) necesitan valerse de una especie de lógica deductiva de las consecuencias concretas que se seguirían a partir de aquellos principios generales del Derecho, pero tales consecuencias no guardarían relación alguna con el "mundo real" ya que su impacto en la conducta de los individuos no sería testeado empíricamente por los jueces formalistas. Tales serían, en pocas palabras, las dificultades inherentes al formalismo jurídico que el AED buscaría superar según su líder intelectual.

Sin embargo el rechazo del formalismo jurídico y en especial de la lógica deductiva que constituye la esencia de la argumentación jurídica no es nueva ni ha sido privativa de los analistas económicos del Derecho. Según MacCormick, el rechazo del formalismo que parece desembocar inevitablemente en una suerte de escepticismo incapaz de brindar una teoría mejor que explique cómo argumentan los jueces es una tendencia siempre latente en la jurisprudencia norteamericana que parece radicalizarse con mayor fuerza en determinadas épocas de su historia ${ }^{21}$. De hecho, Posner sostiene que "la única exigencia para ser formalista es la suprema confianza en las propias premisas y en los propios métodos de derivar conclusiones a partir de ellas”, parafraseando así al célebre juez Oliver Wendell Holmes (uno de los principales mentores del realismo jurídico norteamericano de quien Posner admite haber heredado su desconfianza en el formalismo) ${ }^{22}$.

Pero la lógica deductiva que parte de ciertos principios y normas generales parece constituir la esencia misma de la lógica jurídica, y como MacCormick sostiene, quizás sea la única "teoría" que pueda dar cuenta hasta ahora -con las limitaciones que él mismo señala en la solución de los "casos difíciles"- de la forma en que normalmente se construye un argumento jurídico. Cualquiera que niegue que la lógica deductiva del "formalismo jurídico" constituya el elemento esencial de una explicación coherente y plausible de la adjudicación jurídica, debería poder ofrecer alguna teoría alternativa que pueda dar cuenta cabalmente de cómo argumentan quienes están obligados, por un imperativo constitucional, a solucionar razonablemente los conflictos que se suscitan entre quienes son obligados a acatar normas generales de conducta ${ }^{23}$. La incógnita a despejar aquí es si el AED ha logra-

\footnotetext{
20 Posner (1999) pp. 14-15; 250-252.

21 Maccormick (1997) pp. 36, 40 et passim. Para una caracterización conceptual de la década de los setenta, en la que habría comenzado a gestarse cierto clima de desencanto en el Derecho, véase Fiss (1986) pp. 1-16.

22 Posner (1999) p. 40. Para una demostración de las influencias discursivas, metodológicas y epistemológicas del realismo jurídico norteamericano en el "nuevo" AED, véase Lynn SPEnCER (1998) pp. 51 y ss.

23 Maccormick (1997) pp. 52 y ss.
} 
do elaborar una propuesta coherente, plausible y superadora del formalismo jurídico como base para una teoría de las decisiones judiciales. Esto es lo que analizaré a continuación.

\subsection{LA BÚSQUEda de Un FUndaMENTO ECONÓMICO PARA LA TEORÍA de LA ADJUDICACIÓN}

Hacia 1973 Richard Posner comenzaba a liderar el "nuevo" análisis económico del Derecho y abrigaba entonces la esperanza de poder vencer el formalismo imperante en el Derecho elevándolo, mediante las herramientas del análisis económico, a un estadio científico al que nunca arribaría sin tales herramientas ${ }^{24}$. Posner retrotraía su punto de partida a un artículo exploratorio de Ronald Coase sobre el costo social de la intervención del Estado en la corrección de las fallas de mercado en el que su autor exhortaba a los economistas enrolados en la "economía del bienestar" a tomar en cuenta los costos de dicha intervención y en el que postulaba que en una situación ideal de ausencia de "costos de transacción" el mercado asignaría los recursos hacia su uso más valioso o eficiente sin importar cuál fuese la solución prevista en un sistema de derechos ${ }^{25}$. Sobre el real sentido y el impacto de este artículo, llamado "teorema" algunos años más tarde, se han vertido ríos de tinta y el propio Coase ha mantenido a lo largo de los años una posición un tanto ambigua respecto a su identificación como "obra fundacional del AED"26.

Richard Posner, por su parte, hizo propio el desafío planteado por Coase a los juristas interesados en conocer el aparente impacto de un sistema de derechos en el funcionamiento de una sociedad gobernada por el mercado, y comenzó a revisar prácticamente la totalidad de las áreas comprendidas en el Common Law señalando audazmente que todas ellas llevaban "impresas la estampa del razonamiento económico" por obra de los jueces que durante más de un siglo y medio de jurisprudencia habrían contribuido a forjar con sus decisiones un sistema eficiente de derechos de propiedad, de derechos contractuales, y de responsabilidad civil en casos de daños ${ }^{27}$. Su tesis contenía aspectos descriptivos acerca de cómo había funcionado el Common Law durante un siglo y medio de labor jurisprudente por parte de los jueces, pero también aspectos normativos, pues indicaba cómo debían resolver los jueces aquellos "casos difíciles" o "casos duros", no alcanzados por los precedentes, dando por probado que el formalismo jurídico bastaba para resolver los "casos rutinarios" 28 .

El aspecto propiamente normativo de su propuesta se encuentra desarrollado, básicamente, en un artículo de 1979, en el que intenta definir la maximización de la riqueza como base para una teoría de las decisiones judiciales, y en donde procura poner de manifiesto las aparentes ventajas de su adopción por parte de jueces y legisladores, como también el atracti-

24 Posner (1973) pp. 401-402, 452-458; también Posner (1975) p. 774. En cuanto a su oposición al formalismo jurídico y la "autosuficiencia del Derecho", véase Posner (1999) pp. 424-433.

25 COASE (1960) p. 8.

26 COASE (1978) pp. 206-207; COASE (1998) pp. 73-74. Sobre las dificultades del teorema en su aplicación al Common Law, véase Ellickson (1989) pp. 611-630; Medema (1999) pp. 209-233 y bibliografía allí citada.

27 Posner (2003a) p. 25. Sobre las dificultades propias de esta tesis histórico-descriptiva del Common Law, véase Martínez Cinca (2013) pp. 35-66.

28 Posner (2010b) pp. 35, 44, 46. 
vo moral que ella entraña por encima de las pautas sostenidas por otros sistemas morales. El mayor encanto de la nueva teoría parecía residir, entonces, en la coherencia científica de su propuesta y en la capacidad de poder asumir las consecuencias de las decisiones judiciales y su impacto en el "mundo real", algo que el sentido común reclama constantemente de los jueces y que constituye una "intuición moral ampliamente compartida" ${ }^{29}$. Algunos años más tarde, sin embargo, Posner reconoció las insuficiencias de su teoría de la maximización de la riqueza como pauta normativa, y comenzó a abrazar una especie de escepticismo teórico que de algún modo resultaba contradictorio con su inicial confianza en la razón y en la ciencia. De hecho, a comienzos de los noventa ya reconocía que:

"si los jueces son los actores centrales del drama del Common Law, y juegan también roles decisivos en el Derecho Constitucional y Público [Statutory Law], el fracaso hasta aquí para explicar sus acciones en términos económicos ridiculiza la pretensión del análisis económico de explicar las principales características, tanto institucionales como doctrinales, del Derecho en general, y del Common Law y cualquier otro Derecho creado por el juez en particular. El analista económico posee un modelo acerca de cómo actúan los criminales y las partes contratantes, los causantes de daños y las víctimas de accidentes [...] pero titubea cuando se le pide que formule un modelo de cómo actúan los jueces" ${ }^{30}$.

Las claves de su itinerario intelectual han sido analizadas en algunos trabajos a los que remito en honor a la brevedad ${ }^{31}$. En líneas generales podría decirse que Posner ha abandonado ya la pretensión de fundar la teoría de la adjudicación en un principio arquitectónico de carácter económico, y ha abrazado un escepticismo teórico al que presenta ciertamente como compatible con un pragmatismo liberal y "moderado" [self-constrained pragmatism] en el que si bien no es posible identificar un modelo o estructura racional de principios y reglas conforme a los cuales los jueces podrían tornar razonables y predecibles sus decisiones judiciales, al menos podrían acompañar los procesos sociales y las decisiones políticas que constituyen el engranaje fundamental en la vida de una nación como los Estados Unidos de Norteamérica ${ }^{32}$.

Ahora bien, las dificultades del AED en ese terreno central de la teoría general del Derecho no obedecerían a una barrera levantada en su contra por el formalismo jurídico -y en ese sentido partirían de un diagnóstico equivocado quienes continúan abogando por un Derecho menos formalista y más "realista" para comprender su impacto en la sociedadsino que obedecerían a las propias inconsistencias y debilidades de la teoría de la maximización de la riqueza al adoptar un fundamento sobre el que resultaría casi imposible asentar la tarea de los jueces. Veamos por qué.

\footnotetext{
29 Posner (1979) pp. 110-11; Martínez Cinca (2009) pp. 323-351.

30 Posner (1993) p. 2.

31 Meyerhof Salama (2012); Campbell (2011); Hackney Jr. (2003); Martínez Cinca (2010) pp. 222 y ss. El reconocimiento de las inconsistencias de la teoría de la maximización de la riqueza como teoría de la adjudicación puede verse en POSNER (1999) pp. 370, 384, y especialmente p. 392.

32 Posner (1988) pp. 828-836; Posner (1999) pp. 26, 392; Posner (2003b) p. 47.
} 
El Symposium on Efficiency as a Legal Concern celebrado en 1980 en la Universidad de Hofstra (New York) constituyó una ocasión para que la comunidad de los Legal Scholars de los Estados Unidos de Norteamérica discutiera ampliamente los fundamentos y los límites del enfoque normativo del AED. En esa ocasión Posner fue invitado al debate y llevó una ponencia que generó varias réplicas y contrarréplicas, marcando el inicio de una de las polémicas más agudas en los últimos 30 años de la Filosofía del Derecho norteamericana ${ }^{33}$. En ella, Posner comenzó argumentando que el concepto de eficiencia comúnmente manejado por los economistas era el concepto de optimalidad elaborado por el economista italiano Vilfredo Pareto (1848-1923) ${ }^{34}$. Una asignación de recursos es "Pareto-superior" a otra cuando "al menos una persona está mejor en la primera que en la segunda, y nadie está peor" 35 . Pareto buscaba solucionar, al parecer, el problema de las comparaciones interpersonales de la utilidad (uno de los principales problemas teóricos del utilitarismo), aun cuando el aparente éxito de su propuesta fuera cuestionado seriamente por el economista Amartya Sen (quien algunos años más tarde recibiría el Premio Nobel por sus críticas y propuestas de superación de la economía utilitarista ${ }^{36}$ ). En cualquier intercambio (y una disputa judicial podría entenderse como un "intercambio", ya que en ella las partes "negocian un derecho") es difícil saber si las partes intervinientes experimentan mayor utilidad o si "están mejor" que antes de producirse el intercambio, pero Posner sostiene que si adoptamos el criterio de Pareto, aunque no contemos con un método seguro para comparar utilidades, es lícito pensar que el intercambio ha sido eficiente y que las partes "están mejor" porque han consentido libremente el intercambio. Según Posner, cuando las personas actúan en un mercado libre de restricciones "revelan sus preferencias" en las transacciones, y ello nos permite conocer de manera indirecta cuáles son dichas preferencias. En realidad, esta audaz forma de sortear la dificultad de las comparaciones interpersonales de la utilidad había sido entrevista ya por los autores marginalistas de fines del siglo XIX, particularmente por William Stanley Jevons:

"Una unidad de placer o de dolor es difícil aún de concebir; pero es la magnitud de estos sentimientos la que nos está incitando continuamente a comprar y a vender [...] y es de los efectos cuantitativos de los sentimientos que debemos estimar sus magnitudes comparativas. No podemos conocer más ni medir la gravedad, en su propia naturaleza, de lo que podemos medir un sentimiento; pero, de la misma manera que medimos la gravedad por sus efectos en el movimiento de un péndulo, podemos estimar la igualdad o desigualdad de los sentimientos por las decisiones de la mente humana" ${ }^{37}$.

33 Posner (1980a) p. 487 y ss., también Posner (1980b) p. 775 y ss. Para una visión retrospectiva de la polémica y su incidencia en el pensamiento jurídico norteamericano, véae FISs (1986) pp. 13-14.

34 El principio de "optimalidad paretiana" ha sido también recogido por Robert Alexy en su Teoría de los derechos fundamentales como "imperativo" o "mandato de optimización" en caso de colisión entre principios fundamentales del Derecho; véase AleXY (1993) p. 86 y ss.

35 Posner (1980a) p. 488.

36 Véase su crítica al principio de "optimalidad paretiana” en SEN (1970) pp. 152-157.

37 JeVons (1965) p. 11. 
Al parecer, la comparación interpersonal de las utilidades ha sido un problema para la economía moderna, pero desde Alfred Marshall en adelante los economistas le han asignado a los instrumentos de medición un papel preponderante, dejando de lado las cuestiones de cómo se forman, cuál es el fundamento de los gustos o preferencias de los individuos, y cómo puede medírselos en sí mismos ${ }^{38}$. La economía moderna parecería haberse transformado, entonces, en una ciencia de instrumentos al haber dejado de lado cualquier especulación en torno a la naturaleza o cualidad de los objetos que mide. En términos sencillos se podría decir que la economía moderna ha transformado toda magnitud cardinal en meras magnitudes "ordinales" que poco dicen acerca de su naturaleza o esencia. Sin embargo, esta transformación tiene como consecuencia la imposibilidad de realizar operaciones entre dichas magnitudes ordinales. En efecto, 'uno' más 'dos' es 'tres', pero 'primero' más 'segundo' no es 'tercero', ni ‘bello' más 'menos bello' es igual a 'feo’. Los números ordinales no son aditivos pues las distancias entre estos no son conocidas y por tanto, no son necesariamente constantes ${ }^{39}$.

Las magnitudes ordinales permiten, por cierto, establecer un orden de preferencias de las diversas situaciones y tomar decisiones en casos individuales, pero no permiten, por ejemplo, "agregar" las preferencias de distintos individuos y sumarlas (lo que, al parecer, es uno de los errores conceptuales en que se asienta la teoría de la maximización de la riqueza, ya que apuntaría a la maximización de la riqueza social obtenida por medio de las decisiones judiciales). Como señala Patrick Suppes, la cantidad extensiva (la magnitud cardinal) sí admite adiciones, mientras que la intensiva (que se expresa en escalas ordinales) no las admite ${ }^{40}$.

Haciendo a un lado esta limitación epistemológica de la economía moderna, Posner sostiene, sin embargo, que el recurso al dinero no es solo una salida o artificio métricotécnico, ya que descansa en un "fundamento moral" que le otorga algo más que una mera validez instrumental. Ese fundamento moral es el consentimiento que refuerza la autonomía de las personas, y ello constituiría una base suficiente para fundar una teoría plausible de las decisiones judiciales para los casos "no rutinarios", es decir, los no expresamente contemplados por las leyes o los precedentes jurisprudenciales. Sin embargo, como es obvio que tal consentimiento solo existe en las relaciones contractuales en las que las partes son libres para negociar sus derechos, pero no en las relaciones emergentes del derecho de daños, de inmisiones, ni en muchas otras áreas del Common Law, Posner tuvo que admitir que dicho consentimiento no necesitaba ser expreso ni estar referido a una determinada transacción o intercambio de derechos: bastaba con que las partes intervinientes consintieran las reglas de juego generales bajo las que se gobierna una economía de mercado. Esta argumentación será motivo de análisis en la sección siguiente. Detengámonos, de momento, en la cuestión del consentimiento como fundamento moral de las "mejoras paretianas".

El consentimiento, "un criterio ético acorde a la autonomía kantiana” según Posner, es "la base operacional" del concepto paretiano de eficiencia ${ }^{41}$. En efecto, se supone que si

\footnotetext{
38 Véase Becker y Stigler (1977) pp. 76-90.

39 Guilford (1954) pp. 17 y ss.

40 Suppes (2000) p. 550.

41 Posner (1980a) p. 490.
} 
las partes han realizado el intercambio de manera libre es porque lo han consentido, y el consentimiento contractual es a la vez una "manifestación operacional" de la autonomía defendida por Kant. Posner presupone que los individuos saben lo que más les conviene y optan por ello, lo que es visto y defendido como un valor en sí mismo, al margen de cuál sea el contenido real de sus preferencias ${ }^{42}$. El principio paretiano de eficiencia es meramente instrumental y "profundamente liberal", sostiene Posner, porque nos dice que cualquier cambio es bueno "si beneficia al menos a una persona y no perjudica a nadie", sin la necesidad averiguar cuáles son las preferencias de los individuos en sociedades pluralistas como las nuestras ${ }^{43}$. En definitiva, el enfoque de la "elección racional" sobre el que se asienta la economía neoclásica encajaría bien en los fundamentos de la filosofía práctica de Kant, o sea en la autonomía del sujeto y en la comprensión del Derecho como "conjunto de condiciones que hace compatible el arbitrio de cada uno con el de los demás bajo una ley general de libertad" ${ }^{44}$.

\subsection{Dificultades del Criterio de Pareto en la Resolución de las disputas JUDICIALES}

Ahora bien, la eficiencia instrumental del análisis económico enfrenta algunas dificultades en su aplicación a la tarea de los jueces. En efecto, ¿cómo podría un juez aplicar el principio paretiano de eficiencia cuando debe decidir una disputa entre dos pretensiones concurrentes en torno a las cuales no se ha alcanzado, precisamente, un consenso entre las partes?

Dada la estructura del litigio judicial en que una parte, en la mayoría de los casos, demanda a otra para obtener un beneficio a su costa -al menos en el ámbito del Derecho Privado o Civil, pero específicamente en el Derecho de los Contratos y en el Derecho de Daños que constituyen el corazón del AED- sería casi imposible pensar en una situación de optimalidad paretiana ya que por definición, según Pareto, nadie debería resultar perjudicado tras la adjudicación hecha por el juez. Pero entonces, ¿cómo podría resolver un juez cualquier contienda judicial en la que, en principio, una de las partes gana lo que la otra pierde?

Se podría responder a esta pregunta, siguiendo la línea argumental del "teorema" de Coase, que al margen de lo que los jueces decidan -si hacer lugar o no a la indemnización, desalentando así o incentivando una actividad dañosa- el mercado alcanzará de todos modos la solución eficiente (suponiendo, además, que no existan "costos de transacción”). En resumidas cuentas: más allá de lo que resuelvan los jueces en una demanda por daños, el "teorema” de Coase postula que la víctima le ofrecerá una suma de dinero al causante del

42 Para una crítica de la "autonomía” como un valor en sí mismo, véase Massini Correas (2005) pp. 120 y ss.

43 La racionalidad económica empleada del AED es de tipo "instrumental": en ella los fines se suponen "ya dados" y no se los discute. Sin embargo dicha racionalidad ha sido cuestionada entre los economistas durante las dos últimas décadas, pues al parecer existirían en la Economía criterios más amplios de racionalidad CRESPO (2006) pp. 1-88 e incluso de eficiencia Mercuro y Medema (2006) pp. 68-93 que los empleados por la corriente principal del AED.

44 Posner (1996) p. 103. El Premio Nobel Amartya Sen, por el contrario, ha mostrado las inconsistencias liberales del principio paretiano, ya que "mejorar" a alguien no condice con el antipaternalismo que el liberalismo predica del Estado; véase SEN (1970) pp. 152 y ss. En realidad, el principio de optimalidad de Pareto podría encajar en las principales tradiciones morales de Occidente (incluso la aristotélica), como sostiene PosNer (1996) pp. 103 y ss., y esa versatilidad constituiría hoy una ventaja para una sociedad abierta y pluralista. 
daño para que no continúe con su actividad dañadora aun cuando este tuviese derecho a realizar tal actividad conforme a la ley, y el causante del daño hará lo mismo con la víctima en caso de que la ley le reconozca a ella el derecho a no ser dañado, siempre y cuando la suma de dinero sea: 1) en el caso del causante del daño sin derecho a dañar, una suma menor a las pérdidas que experimentaría por cesar su actividad pero mayor al monto de los daños que experimentaría la víctima; y 2) en el caso de la víctima sin derecho a indemnización, una suma menor al monto de sus daños pero mayor a las pérdidas que experimentaría el causante por cesar su actividad.

Pero este postulado parece desconocer el impacto de las sentencias judiciales en el mundo cuyo "realismo" el AED pretende descubrir. En efecto, si los corolarios del "teorema" de Coase fuesen correctos, las demandas y los litigios deberían haber disminuido -cuando no acabado- hace ya tiempo en una economía de mercado, máxime en una economía como la de los Estados Unidos de Norteamérica y en un sistema legal como el Common Law en el que el principio de eficiencia ha tenido, supuestamente, tanta influencia como Posner sostiene que ha tenido. Los litigios deberían haber disminuido de los años setenta en adelante, ya que si la eficiencia ha sido un principio al menos "bueno por defecto" desde que Posner y su escuela irrumpieron en la jurisprudencia norteamericana, debería haberse advertido por cierto una disminución en el índice de demandas, de litigiosidad y del "costo judicial" del sistema. Sin embargo todos esos indicadores han aumentado en las últimas décadas como el propio Posner admite con cierto desconcierto ${ }^{45}$. Eso quiere decir que la gente, las empresas, el gobierno y las corporaciones siguen acudiendo a los tribunales cada vez en mayor medida y que se dictan sentencias reales y efectivas que implican que alguien pierde y otro gana (y la inmensa mayoría de las veces el que pierde, pierde dinero, cuando menos en el pago de los honorarios profesionales). Que el perdedor continúe después con su actividad dañadora porque ella es más rentable, aun cuando tenga que afrontar los daños, no quita que perdió y que resultó efectivamente perjudicado por la demanda.

En consecuencia, una teoría de la asignación eficiente como la ensayada por Posner se enfrenta con un dilema: o bien abandona los corolarios del "teorema" de Coase como base para dicha teoría, o bien intenta fundarla sobre un concepto de eficiencia más amplio capaz de superar la dificultades del "concepto paretiano que subyace al teorema" y a la mayor parte de "los análisis realizados por los economistas para afirmar su validez" 46 . Como veremos enseguida Posner se inclinó por la segunda alternativa, confiando todavía en las posibilidades teóricas de un trabajo como el de Coase cuyas "intuiciones” ya han sido rebatidas por un "enorme número de pruebas en su contra, muchas de ellas altamente técnicas", como sostiene Medema. Para este autor, la negación del "teorema” hubiera sido de mucha "más trascendencia para el AED", pues si el sistema de derechos es irrelevante para una asignación eficiente de los recursos no se advierte cuál es, entonces, el sentido de fundar

\footnotetext{
45 Véase Posner (2003a) pp. 603 y ss. En (1999b) pp. 59 y ss. reconoce que los litigios en la jurisdicción federal aumentaron un $686 \%$ entre 1960 (el año de publicación del "teorema") y 1983.

46 Medema (1999) p. 213. Este autor sostiene que las aplicaciones del "teorema" ensayadas por Posner en cuanto teoría adjudicativa son insostenibles, y que la contribución de Coase al movimiento del Law and Economics se ha limitado más bien a la necesidad de discutir las aparentes ventajas de un sistema de derechos de propiedad por sobre un sistema de reglas de responsabilidad y viceversa (pp. 223-226).
} 
una teoría eficiente de las decisiones judiciales. En su opinión, el legado más importante del "teorema" han sido las investigaciones a que dio lugar tendientes a "conocer la naturaleza de los costos de transacción y su impacto en la operación del sistema económico" 77 .

Por su parte, el profesor Jules Coleman ha mostrado que la teoría de la maximización de la riqueza sostenida por Posner parece asentarse en un error conceptual no advertido, ab initio, por el líder intelectual del AED. El error consiste en no distinguir la diferencia esencial que existiría entre: a) solucionar una controversia específica mediante el criterio de "superioridad" paretiana, y b) apuntar a un "ideal de máximos" como el que aspiraría a realizar la "optimalidad" paretiana que Posner parece tener en la mira cuando postula la maximización de la riqueza como pauta judicial para alcanzar un estado de cosas socialmente deseable desde el punto de vista de la eficiencia ${ }^{48}$. En otras palabras, Posner habría asimilado y confundido un criterio de elección colectiva -como es el concepto de optimalidad paretiana o el de Kaldor-Hicks que en seguida analizaré, ambos destinados a solucionar un problema teórico de la economía del bienestar, y en ese sentido asimilables más bien a "directrices" en el sentido de Dworkin - con un criterio propio de la racionalidad individual -como es la pauta maximizadora de la riqueza, destinada a encontrar la solución más eficiente en una disputa entre partes-. De este modo, habría caído en el error de suponer que el resultado óptimo de cualquier regla de decisión que pretenda realizar una "mejora paretiana” podría identificarse o determinarse a priori, un error que, según Mishan, se funda en la "creencia general" de que es posible identificar de antemano la solución óptima (desde el punto de vista social) en cualquier arreglo entre partes ${ }^{49}$.

En efecto, en una situación de "superioridad paretiana" es posible reasignar recursos en función de un aumento de utilidad en una de las partes sin causar una "desutilidad" a la otra, sin necesidad de atender al resultado sobre la utilidad agregada de toda la sociedad; en cambio, en una situación de "optimalidad" no sería posible reasignar recurso alguno sin perjudicar a alguien más en la sociedad, pero esa situación ideal a la que la maximización de la riqueza apuntaría, según Posner, no podría alcanzarse siguiendo el criterio de no perjudicar a otro en las transferencias o reasignaciones parciales que los jueces realizan, y supondría, además, que quien "decide" en qué dirección debe realizarse la mejora (el juez en este caso) posee un cúmulo de información que en realidad ningún agente de planificación económica es capaz de poseer (con menos razón un juez). Según Coleman, la persecución de la eficiencia por parte de los jueces no necesariamente acarrea eficiencia a la sociedad, y no existe forma alguna de afirmar con exactitud si una decisión tomada por un funcionario cualquiera, en una controversia particular, impactará de manera eficiente en la economía de la sociedad a largo plazo $^{50}$. La afirmación de Coleman resulta comprensible si se toma en serio uno de los postulados centrales de la economía neoclásica: ningún agente económico (y menos aún un juez) posee la omnisciencia suficiente para conocer en qué medida su decisión impactará eficientemente en el mercado y en el sistema general de bienes y servicios.

\footnotetext{
47 Medema (1999) pp. 215, 220 y 228.

48 Véase Coleman (1984) pp. 649-679.

49 Mishan (1967) pp. 258, 275.

50 Coleman (1984) pp. 669-670.
} 
Por otro lado los jueces, por imperio de la Constitución (tanto en los Estados Unidos de Norteamérica como en Chile) no han sido revestidos de un poder jurisdiccional para maximizar la riqueza social ni para promover el bienestar general de la población, ya que en todo caso esa es una tarea propia del Poder Legislativo (suponiendo que dicho poder cuente con la información adecuada para saber cuál es la situación de eficiencia óptima en un determinado mercado). En ese sentido Posner (y según Coleman también los analistas económicos del Derecho en general) parecen haber confundido los roles institucionales establecidos por la Constitución en un sistema republicano de gobierno:

"El punto central, sin embargo, es que en la visión de los economistas, la ventaja comparativa de las cortes reside en promover la eficiencia, mientras que la ventaja comparativa de las legislaturas reside en hacer justicia, lo que equivale a distribuir la riqueza para promover una mal definida concepción de equidad. Esto parece constituir una reversión sin par de los roles institucionales" 51 .

De un modo similar a lo expresado por Medema, Coleman sugiere que el "teorema" de Coase no podría ser tomado como base para una teoría de las decisiones judiciales ${ }^{52}$. En efecto, si bien es cierto que en un segundo corolario de su trabajo Coase admitía que en la situación más realista en que existiesen efectivamente "costos de transacción" las autoridades gubernamentales deberían imitar la "lógica del mercado" (procurar que los recursos graviten hacia su uso más valioso), lo cierto es que una cosa es afirmar, como hace Coase, que las partes negociarán al margen de cuál sea la estructura de derechos o las soluciones legales para alcanzar la solución que más les convenga a ellos (la más eficiente), y otra cosa es tener que obligar a un juez a imitar el resultado (no el proceso, pues es imposible) de esa negociación. Al tener que imitar el resultado de lo que hubiese sido una negociación, la naturaleza del asunto se transforma sustancialmente, pues el juez debería poder imaginar a qué solución habrían arribado las partes si hubieran podido negociar, aun admitiendo que esa solución habría sido la más eficiente pues quien valorase más el derecho en cuestión lo habría terminado "comprando" de un modo u otro si él no hubiese resultado ser su titular conforme a la ley vigente. Pero precisamente ese criterio resulta inadmisible para un juez, pues el juez debe decidir quién es el titular del derecho conforme a la ley y no conforme a quién estaría dispuesto a desembolsar más dinero por él en una hipotética transacción. El juez no podría apelar al criterio de la eficiencia en la adjudicación ni siquiera en los casos de radical incertidumbre generada a causa del silencio o de la oscuridad de la ley, pues en esos casos el juez se vale de métodos propios del razonamiento jurídico como son los argumentos por analogía o por los principios generales del Derecho, incluso en un sistema jurídico que en principio parecería estar dotado de mayor incertidumbre, como el Common Law ${ }^{53}$.

51 Coleman (1984) p. 677.

52 Coleman (1984) p. 669.

${ }^{53}$ Dworkin (2002) pp. 72 y ss. Para un análisis de las razones por las cuales, en el sistema del Common Law, los jueces tendrían, en principio, mayores facultades para crear Derecho que los jueces de un sistema codificado, y gozarían, incluso, de mayor discrecionaldad para aplicar el Derecho vigente, véase Yowell (2012) pp. 493, 497 y $503-510$. 
Pero además existiría una seria dificultad operativa en la aplicación judicial del principio de "optimalidad" paretiana. Si efectivamente Pareto buscaba la manera de sortear el problema de la comparación interpersonal de las utilidades -mediante el cálculo de magnitudes ordinales, no cardinales- no es del todo claro, sin embargo, cómo funciona operativamente la fórmula, es decir, cómo se puede determinar quién está "mejor" o "peor" en diferentes situaciones. En ese sentido el juez Anthony D’Amato sostiene que los economistas han realizado un "juego de manos” al erigir el dinero en el patrón de medida de todos los valores, porque en realidad el único valor que el dinero mide es nada más que "el valor del dinero" 54 . Si, por ejemplo, de dos padres divorciados que disputan la tenencia de sus hijos uno de ellos está en condiciones de invertir en su crianza más dinero que el otro, eso no significa que el más pudiente valore "más" la crianza de sus hijos que el otro, y ciertamente no podría constituir una razón suficiente para asignarle el derecho a la tenencia por más eficiente que eso sea en términos de riqueza (aun suponiendo que la inversión en la crianza redundaría en un mayor beneficio social a futuro). De igual modo, suponer -como hace Posner- que el amo valoraba más la fuerza de trabajo que el esclavo porque "invertía” en su manutención más dinero que el propio esclavo, y que por eso en la época preindustrial tuvo "más sentido económico" el derecho a la esclavitud que el derecho al trabajo libre, es una afirmación arriesgada que solo desde una visión sesgada de la historia se podría sostener ${ }^{55}$. En tanto clave interpretativa del Derecho, semejante visión parece dejar de lado otros factores que inciden en la formación de las leyes y de las instituciones jurídicas en general ${ }^{56}$.

En relación con el problema de qué es lo que el dinero realmente mide (un problema bastante antiguo que el propio Aristóteles no pudo resolver satisfactoriamente ${ }^{57}$ ), los economistas modernos parecen haber adoptado un punto de vista instrumental en el que la vieja cuestión del "valor" ha sido dejada de lado y en el que no interesa si el valor de las cosas reside en cualidades objetivas que pertenezcan a las cosas mismas o en una apreciación subjetiva de quien valora la cosa en virtud de diversos factores que los escolásticos llamaron "componentes subjetivos del valor" (necessitas, virtuositas, placibilitas, entre otros). Al limitarse a trazar una curva que refleje la utilidad marginal decreciente del dinero, los economistas modernos admiten que no existe forma alguna de saber si las curvas de diversas personas son iguales o diferentes en altura y en pendiente, de manera que no podemos ni siquiera saber quién valora más el dinero por sí mismo. Pero entonces, si el dinero no puede medir con exactitud el único valor que supuestamente podría medir (su propio valor), ¿cómo puede erigirse en la pauta de una asignación eficiente de los recursos? Posner reconoce que los economistas se manejan solo con "conjeturas" en la valoración interpersonal del dinero, pero que a juzgar por el comportamiento externo de quienes poseen el dinero en abundancia, deberíamos "suponer" que los ricos valoran el dinero más que los pobres ${ }^{58}$. A partir de tales conjeturas, Posner sostiene que si la maximización de la riqueza ha de

\footnotetext{
54 Véase D’Amato (1992) p. 764, nota a pie no 22.

55 Véase Posner (1979) p. 125; Posner (1998) pp. 187 y ss.

56 Para un análisis de este y otros ejemplos del análisis económico aplicado a la evolución general de las leyes y los derechos, véase MarTínez Cinca (2012) pp. 29-64, especialmente pp. 48-49.

57 Véase Martínez Cinca y Crespo (2013).

58 Entre otras cosas, porque los ricos no malgastan el dinero en juegos de azar. Véase Posner (2003a) p. 470.
} 
servir de base para una teoría de la adjudicación o asignación de derechos en los "casos difíciles", entonces habrá que entender la riqueza como "el valor en dólares o el equivalente en dólares de cualquier cosa en una sociedad" 59 . La riqueza, así entendida, se mide a partir de lo que un individuo estaría dispuesto a pagar por algo o, si ya lo posee, por lo que estaría dispuesto a recibir para desprenderse de ello.

Sin embargo la conmensuración de los derechos mediante el baremo universal del dinero constituye solo en apariencia una solución al problema de los "casos difíciles". Ni el dinero ni la riqueza parecen estar realmente en el centro del debate cuando se pretende dar una solución jurídica a los "casos difíciles". Pero además recientes investigaciones realizadas en el marco de diversos experimentos señalan que ni siquiera es idéntico el valor que las personas asignan a un bien cuando efectivamente lo poseen que cuando no lo poseen (endowment effect) y menos aún cuando esa posesión es el resultado de una asignación hecha por juez en la solución de una controversia ${ }^{60}$. Por eso el juez D’Amato concluye que, "puesto que los economistas no pueden realizar comparaciones interpersonales de utilidad, tampoco pueden señalar el camino hacia una decisión correcta en ninguna disputa jurídica real" ${ }^{61}$.

\subsection{Cambio de fundamento y nUEVAS Dificultades}

Las dificultades señaladas llevaron a Posner a buscar un criterio de eficiencia más adecuado a las características propias del sistema jurídico. El nuevo criterio de eficiencia adoptado fue el de los economistas Nicholas Kaldor y J. R. Hicks ${ }^{62}$. Según este criterio (también llamado "Pareto-potencial") no hace falta que nadie sea perjudicado por un cambio en la asignación de los recursos, sino solo que "el incremento en valor sea lo suficientemente amplio como para que los perjudicados sean plenamente compensados" ${ }^{33}$. Para Kaldor y Hicks una situación sería más eficiente que otra si pudiese introducirse un cambio en la legalidad existente tal que se beneficiase a una persona aunque se perjudicase a otra $\mathrm{u}$ otras con tal que el beneficiado pudiese resarcir potencialmente al o a los perjudicados. Analicemos un poco más de cerca este nuevo criterio de eficiencia.

Como Posner señala, Kaldor y Hicks asumen de manera más realista el impacto de las políticas en el mercado y no descartan la causación de un "perjuicio", pero al mismo tiempo posibilitan que el gobierno compense dicho perjuicio de una u otra forma, a corto o a largo plazo. En realidad, Kaldor y Hicks habían procurado revisar en 1939 los fundamentos teóricos sobre los que se asentaban las políticas welfaristas, pero Posner propone expresamente dejar de lado la cuestión de si el gobierno debe o no compensar a los perjudicados, pues para el propio Kaldor esa era "una cuestión política sobre la que el economista, qua economista, apenas podría pronunciar una opinión”64. De ahí que el criterio

\footnotetext{
99 Posner (1979) p. 119.

60 Jolls et al. (1998) p. 1498.

${ }^{61}$ D’Amato (1992) p. 760.

62 Kaldor (1939) pp. 549 y ss.; Hicks (1939) pp. 696 y ss.

63 Posner (71998) p. 91. La primera edición de esta obra data de 1981.

64 Kaldor (1939) p. 550.
} 
de Kaldor-Hicks sea más riguroso analíticamente, pues permite discutir "por separado las cuestiones de la asignación y la distribución de los recursos", como sostiene Posner ${ }^{65}$.

En realidad, el fundamento de este nuevo criterio sigue siendo el consentimiento autónomo, pero ahora se trata de un consentimiento à la Rawls. En efecto, de un modo similar a la propuesta por el autor de Una Teoría de la Justicia, Posner sostiene que todo individuo que acepte formar parte de una sociedad debe también aceptar las reglas con que esta se maneja. Como la sociedad no es otra cosa que un mercado, lo que el individuo acepta implícitamente son las reglas con que el mercado se maneja, y entre ellas destaca sobre cualquier otra la "regla del equilibrio", que constituye uno de los supuestos teóricos del mercado de competencia perfecta. El equilibrio de mercado supone que alguien podrá perder en algún caso particular, en ocasión de alguna transacción o intercambio concreto, pero el propio mercado lo compensará -al menos potencialmente-garantizándole un precio justo que no es otra cosa que el precio de equilibrio entre la oferta y la demanda, ya que nadie tiene poder suficiente como para alterar o fijar los precios. Vale decir, al aceptar ex-ante reglas que son iguales para todos estaría aceptando implícitamente la posibilidad de perder, y ello significa que las pérdidas son consentidas, a menos que decida retirarse del juego.

"Muchas de las pérdidas involuntarias, y en apariencia no compensadas, experimentadas en el mercado o toleradas por las instituciones que toman el lugar del mercado allí donde el mercado no puede funcionar efectivamente, están plenamente compensadas ex-ante, y por ende consentidas en el sentido antes expresado" ${ }^{66}$.

Uno de los rasgos centrales de la maximización de la riqueza como teoría adjuticativa es su pragmática versatilidad. Dicha versatilidad le permite encajar bien en las principales tradiciones morales de Occidente, como apunta Posner, pero incluso también en una teoría moral como la de Rawls a la que Posner ha combatido por tratarse de una propuesta "igualitarista" con poco sentido económico ${ }^{67}$. Pero lo más problemático para una teoría económica de la adjudicación es que las dificultades operacionales que el principio paretiano de eficiencia no logra superar parecen subsistir en la versión kaldoriana, porque como Amartya Sen ha señalado, el principio de Kaldor-Hicks o bien es poco convincente o bien termina siendo redundante ${ }^{68}$. En efecto, el criterio de Kaldor-Hicks presupone que debe existir ex-ante la posibilidad potencial de compensar al perjudicado, pero no dice que efectivamente deba serlo: deja la decisión moral de compensarlo en manos del gobierno. Ahora bien, para quien no fue efectivamente compensado ex-post resulta poco convincente el consuelo de pensar que

\footnotetext{
65 Posner $\left({ }^{7} 1998\right)$ p. 92.

66 Posner $\left({ }^{7} 1998\right)$ p. 94.

${ }^{67}$ Véase Posner (1979) p. 118. En otra parte sostiene: "El resultado de todas estas incertidumbres es que la teoría rawlsiana de la justicia parece bastante compatible por un lado con un socialismo rampante, y por el otro, con un «laissez-faire» capitalista, dependiendo todo de cuánta aversión al riesgo asumamos que los individuos poseen en la posición original, de cuán estrechamente definamos el grupo de los menos aventajados en cuyo interés las políticas deben operar, y de cuán efectivas consideremos las instituciones públicas referidas al mercado libre” Posner (2003) p. 475.

68 SEN (2004) p. 33, nota a pie no 4.
} 
podría haber sido compensado, aunque de hecho no lo haya sido. Pero si resulta finalmente compensado se produce entonces una simple mejora paretiana (nadie resultó perjudicado), con lo que el criterio de Kaldor-Hicks termina siendo redundante, como señala Sen.

¿Por cuál de las dos opciones se inclina Posner? Al parecer por la primera, es decir, por la posibilidad de consolar al perjudicado con la idea de que las reglas del mercado son ciegas y no se ensañan con nadie en particular (porque a cualquiera podría haberle tocado perder) y en todo caso porque aseguran condiciones imparciales bajo las cuales, en otra ocasión, se podrá ganar. En el fondo, el argumento de Posner es que resulta preferible perder por efecto de las reglas imparciales del mercado que no por las decisiones arbitrarias de los jueces, postulando que la discrecionalidad judicial alcanzaría un nivel deseable de imparcialidad si los jueces "imitaran la lógica del mercado" (como en resumidas cuentas expresa el segundo corolario del "teorema" de Coase).

Sin embargo, algunas de las insuficiencias normativas del criterio kaldoriano pueden apreciarse mejor en una figura jurídica que Posner ha señalado como creación y diseño exclusivo de los jueces maximizadores de la riqueza social ${ }^{69}$. Se trata de la institución del Efficient Breach of Contract, que podría traducirse como "resolución eficiente del contrato por incumplimiento", y en la que pueden advertirse algunos de los riesgos de imitar la lógica ciega del mercado ${ }^{70}$. Supongamos el siguiente caso. A es un productor de uvas y celebra un contrato con la bodega B mediante el cual se compromete a venderle su producción al cabo de la cosecha. El contrato incluye cláusulas resarcitorias claras y definidas para el caso de incumplimiento. Entre la celebración del contrato y la cosecha aparece una bodega $\mathrm{C}$ y le ofrece al productor por sus uvas una suma superior a la pactada con $\mathrm{B}$, a punto tal que con esa suma A alcanza a cubrir el resarcimiento estipulado con B y a embolsar, incluso, un beneficio neto. La pauta judicial maximizadora del Efficient Breach of Contract incentivará al productor a que opte por la resolución del contrato con B y venda sus uvas finalmente a C. La riqueza social se habrá maximizado no solo por el beneficio neto del que A se apodera al contratar con $\mathrm{C}$, sino porque además $\mathrm{B}$ no ha experimentado perjuicio alguno, ya que a cambio de la prestación en especie obtuvo una suma de dinero en concepto de compensación. Al parecer, los criterios de eficiencia, en cualquiera de sus versiones (paretiana o kaldoriana), han quedado satisfechos.

Ahora bien, Posner había sostenido en 1979 que la maximización de la riqueza, como pauta moral y jurídica de una sociedad, favorecería el desarrollo de una constelación de "virtudes protestantes" tales como el cumplimiento de las promesas, la veracidad, la lealtad y la honestidad -entre otras- que reducirían los costos de transacción referidos a la "policía de los mercados", a la litigiosidad y al detallismo en la contratación ${ }^{71}$. Sin embargo, la figura del Efficient Breach of Contract no parecería favorecer un "clima" propicio para los

\footnotetext{
69 Posner (1992) p. 935.

70 En el Derecho Civil argentino, por ejemplo, existe la figura de la "resolución del contrato por incumplimiento" que es una creación de la dogmática jurídica con claro apoyo en el texto de la ley (art. 1204 y concordantes del Código Civil argentino). Sin embargo las consideraciones de eficiencia y maximización no han tenido lugar alguno en la creación de esa institución; veáse el capítulo 4 [“Concepto, fundamento, naturaleza y función de la resolución por incumplimiento"] de MiQuel (1986).

71 Posner (1979) p. 124.
} 
negocios pues no desincentiva de manera suficiente el incumplimiento de las obligaciones contractuales, y ello atentaría, en última instancia, contra la maximización de la riqueza social. Pero además es difícil advertir cómo este uso adjudicativo del criterio de eficiencia contribuiría a disminuir los costos de transacción que Coase señalaba en su análisis teórico del sistema jurídico. En efecto, una teoría de la adjudicación que solo midiese la riqueza en términos monetarios (como en el caso del Efficient Breach of Contract) parecería favorecer el aumento de litigiosidad, porque es lógico pensar que en el ejemplo anterior B demandará al productor A por incumplimiento, a menos que uno piense con algo de ingenuidad que A abonará de manera espontánea el resarcimiento a B sin que a ello lo obligue una sentencia previa. Si lo que mueve al productor es el afán de lucro, A especulará hasta el último momento en obtener la máxima ganancia y evitará resarcir a B hasta que un juez se lo ordene. ¿Por qué habría de hacer lo contrario?

Uno de los mayores problemas de la maximización de la riqueza como base para una teoría de la adjudicación quizás resida en el enfoque puramente instrumental que Posner quiso imprimirle a una jurisprudencia que fuese capaz de imitar la lógica del mercado, pues una jurisprudencia sin un sistema ordenado y jerárquico de principios sustanciales de justicia, o de principios subordinados a la sola consecución de la riqueza, no parece viable. Según D’Amato, dicha jurisprudencia se movería en el ámbito de los disputas reales resueltas por los jueces como "un fontanero lo haría en una cirugía de corazón”72. Se trata de una comparación sin duda exagerada, pero que revela, en el fondo, algo más que un simple apego al formalismo por parte de los jueces que la rechazan. D'Amato es un juez norteamericano que siendo estudiante de Derecho fue al mismo tiempo condiscípulo de Posner en las aulas de Harvard (de donde este último egresó summa cum laude en 1962), que conoce a fondo los problemas que enfrenta el formalismo jurídico en la adjudicación o solución de los "casos difíciles", y que sin embargo sostiene que los jueces norteamericanos no han hallado en el AED un principio de solución a esos problemas.

En resumidas cuentas, una de las mayores dificultades de la maximización de la riqueza como pauta judicial de asignación o adjudicación de los derechos parece haber estado en el "acta de nacimiento" del AED. En efecto, como D’Amato señala con algo de amarga ironía, el "teorema” de Coase logró que el AED naciera "muerto en las entrañas de su madre" aunque muchos de sus partidarios "no hayan caído aún en la cuenta"73. En cualquiera de los dos supuestos teóricos de Coase -ausencia o presencia de costos de transacción- la consecuencia directa de sus postulados es que una economía de mercado guiada por el principio de racionalidad es inmune a la asignación jurídica de los recursos (o asignación de derechos). De un modo más sencillo, Coase postulaba que si los costos de transacción son insignificantes no importaría cuál de las partes tendría derecho a qué cosa porque el mercado haría su trabajo de cualquier modo (se alcanzaría la solución más eficiente por vía de la negociación), y en un segundo postulado agregaba: "los jueces deberán imitar al mercado si los costos son significativos”. Pero el punto clave en este segundo postulado es: ¿qué abogado o

\footnotetext{
72 "Apelar a la economía para decidir casos individuales es como apelar a un fontanero para una cirugía de corazón” D’Aмato (1992) p. 760.

73 D’Aмато (1992) p. 761.
} 
juez del mundo real cumplirá con semejante mandato? Para un abogado significará la reducción de sus ganancias cuando no la pérdida de su fuente de ingresos, porque precisamente un abogado "hace su negocio" en los costos de transacción. Para un juez sencillamente significará, como antes señalé, la imposibilidad de imitar la solución que alcanzaría el mercado al no disponer de la información suficiente para saber qué asignación de derechos redundará en la maximización de la riqueza social ni tampoco cuál hubiese sido la solución más eficiente a la que habrían arribado las partes en una hipotética negociación ${ }^{74}$. En definitiva la maximización de la riqueza parece valerse de un "lenguaje circular, vacío y sin referencia alguna a la realidad", algo que el mismo Posner reconoce, sin embargo, como una virtud de la ciencia económica ${ }^{75}$. Frente a esta dificultad conceptual y lingüística es posible entender, de alguna manera, por qué muchos juristas no han encontrado en el AED respuestas satisfactorias a las limitaciones del formalismo jurídico para la solución de los "casos difíciles". De hecho Ian Shapiro ha mostrado en un riguroso estudio analítico cómo la jurisprudencia efectiva de Richard Posner, es decir, su labor jurisprudente al frente del Séptimo Circuito de Apelaciones de los Estados Unidos de Norteamérica por más de un cuarto de siglo, contradice abiertamente sus principales propuestas reformadoras de la jurisprudencia en claves de eficiencia o maximización de la riqueza. En efecto, Shapiro ha pretendido mostrar que, en tanto juez, el principal exponente intelectual del AED no ha podido llevar a la práctica sus postulados teóricos e intelectuales más importantes. Según Shapiro este hecho singular debería servir como muestra suficiente de la inaplicabilidad del AED por parte de los jueces, ya que si la "teoría se encuentra desacreditada en su propio castillo, bien podemos olvidarnos de las construcciones periféricas más allá del foso"76.

Al margen de apreciaciones como estas, parece indudable que la teoría adjudicativa de la maximización de la riqueza debe ofrecer alguna solución a las dificultades señaladas si no quiere pasar a la historia como un nuevo "paso en falso" de la jurisprudencia norteamericana $^{77}$.

74 Resulta significativo advertir que ya CALABRESI (1968) p. 69, uno de los "padres fundadores" del AED, advertía la necesidad de acudir a otras pautas de adjudicación allí donde los datos económicos no permitiesen asegurar cuál sería la solución eficiente.

75 POSNER (1987b) p. 1.

76 SHAPIRO (2005) p. 136. De la página 137 en adelante, Shapiro enumera una larga lista de casos fallados por el jurista de Chicago que irían en una dirección contraria a la propuesta por el AED en un área que ha sido, precisamente, el núcleo central del modelo: Antitrust Law. Véase también el libro editado por Robert Blomquist y prologado por el propio Richard Posner. Posner (2010a) en el que se recogen extractos de sus principales opiniones y dictámenes como juez a lo largo de 25 años, y en el que no existen casi referencias al análisis económico del derecho ni a la teoría de la maximización de la riqueza como pauta de adjudicación de derechos.

77 La expresión "paso en falso" de la jurisprudencia norteamericana ha llegado a ser un lugar común para identificar "la revuelta contra el formalismo", y como tal, es una réplica irónica a un célebre artículo en el que Karl Llewellyn convocaba a los juristas norteamericanos a dar un nuevo paso en pos del "realismo" de la jurisprudencia; véase LleWELLYN (1930) pp. 431-465. Para una renovada defensa del realismo norteamericano véase LEITER (2011). 


\section{RACIONALIDAD INDIVIDUAL, ELECCIÓN COLECTIVA Y ADJUDICACIÓN JURÍDICA}

Es probable que lo expuesto hasta aquí revele las insuficiencias teóricas de la maximización de la riqueza como pauta para la asignación de derechos en un ámbito de problemas y en un lenguaje más bien propios de la ciencia económica en el que los juristas y profesionales del Derecho no parecen moverse con natural soltura. En efecto, la imposibilidad de comparar utilidades y de operar con magnitudes ordinales, la inapropiada sustitución del concepto de superioridad paretiana por el de optimalidad paretiana en la resolución de disputas individuales, la imposibilidad de la valoración interpersonal del dinero, y la "irrealidad" de los corolarios del teorema de Coase, no parecen constituir problemas en los que una teoría plausible de la adjudicación jurídica tenga, en principio, interés alguno.

Sin embargo, a la base de todas estas dificultades expresadas en el lenguaje y en el ámbito de la ciencia económica reside un problema fundamental de la teoría de la adjudicación que ha sido identificado y solucionado, en parte, por Ronald Dworkin. Se trata, sin más, del problema de querer dar una solución a los "casos difíciles" aplicando "directrices" (policies) económicas en lugar de "principios" jurídicos. Como intentaré señalar brevemente en esta sección, esa distinción guarda relación con la pertinente distinción entre la racionalidad individual con la que se manejaría un agente económico (el juez) y los estándares de la elección colectiva con la que deberían manejarse los cuerpos colegiados (legislaturas) que representan la voluntad popular.

En un trabajo pionero más tarde incorporado (con algunas adiciones) al cuarto capítulo de su obra «Los derechos en serio», Dworkin ha señalado que no es posible resolver un "caso difícil" -en el que ninguna regla establecida de Derecho impone una determinada solución- invocando una directriz económica como la eficiencia o la maximización social de la riqueza. En efecto, así como no resulta ajustado a Derecho el sacrificio de los derechos de un hombre inocente en virtud de un deber nuevo impuesto por la ley luego del hecho del proceso, así tampoco resulta ajustado a Derecho sacrificar su propiedad en aras de una mejora colectiva de la riqueza social ${ }^{78}$. La razón fundamental de esta improcedencia radica en el carácter "distributivo" de los principios en función de los cuales deben resolverse los "casos difíciles", frente al carácter "estratégico" de las directrices económicas o políticas. El carácter "distributivo" de los principios jurídicos exige, en efecto, que los derechos que se reconocen en cabeza de un individuo sean reconocidos a todos los individuos por igual, a punto tal que sería posible descubrir qué derechos podrían efectivamente poseer las personas -lege ferenda- con solo atender aquellos argumentos que, en principio, harían prosperar su demanda judicial por parte de todos los miembros de la sociedad ${ }^{79}$. Por el contrario, las directrices persiguen objetivos colectivos y estratégicos, en virtud de los cuales es legítimo imponer, mediante los mecanismos de la elección colectiva por la que se rigen los cuerpos colegiados con representación popular (legislaturas), el sacrificio de los intereses de un de-

\footnotetext{
${ }^{78}$ DWORKIN (1975) p. 1061.

79 Dworkin (1975) p. 1067. De ahí que la expresión "derechos programáticos" constituiría un contrasentido para Dworkin.
} 
terminado grupo de individuos en aras del bienestar colectivo. En consecuencia, los jueces deben decidir los "casos difíciles" conforme a principios jurídicos de carácter distributivo, y no según directrices económicas de carácter estratégico, si es que la exigencia básica de separación de poderes en un Estado de Derecho ha de conservar, todavía, algún sentido.

En contra de lo que Posner sostiene, si el célebre juez norteamericano Learned Hand pudo resolver un célebre caso de negligencia en el Common Law mediante la aplicación de una fórmula en apariencia económica (la imputación del deber de reparar a aquel que hubiese podido evitar el daño a menores costos, en términos generales, descontando la probabilidad de que el daño ocurriese efectivamente), eso no significa que haya resuelto el caso aplicando una directriz en lugar de un principio jurídico, pues lo que ese caso señero consagra ${ }^{80}$ es simplemente un derecho abstracto a la reparación que le asiste a cualquier persona en virtud del viejo principio jurídico de "no obtener una ventaja a causa de un perjuicio injustamente causado a otro”. Como Dworkin sostiene, en efecto, no existe espacio alguno en ese principio (ni en la estructura misma de la litis) para considerar los costos y beneficios de potenciales involucrados ni menos aún de toda la sociedad (como pretenden los criterios paretianos o kaldorianos), sino solo los costos y beneficios de aquellos que son partes en el proceso ${ }^{81}$. La fórmula de Hand y sus versiones más sofisticadas no constituyen, en definitiva, un argumento basado en directrices de eficiencia, utilidad, o algo parecido, pues no subordinan un derecho individual a ningún objetivo colectivo o social: simplemente proporcionan un mecanismo para resolver demandas o pretensiones concurrentes en torno a un derecho abstracto que, en caso de ser reconocido, deberá ser reconocido a todos los individuos por igual ${ }^{82}$.

Finalmente, la tesis de que, conforme a una sana teoría adjudicativa que honre la separación de poderes propia de un Estado de Derecho, los jueces deberían resolver los "casos difíciles" aplicando principios jurídicos y no meras directrices, también es puesta en evidencia mediante la pertinente distinción entre la racionalidad individual de un agente económico (el juez) y los estándares de la elección colectiva propia de los cuerpos colegiados (legislaturas). En efecto, la racionalidad individual con la que un juez se maneja, según Posner, se asienta en una serie de supuestos que, en principio, parecen incompatibles con los estándares de la elección colectiva (el egoísmo o autointerés frente a la cooperación o altruismo, por ejemplo ${ }^{83}$ ), y esa incompatibilidad se torna aún más problemática cuando el propio Posner pretende -aun después de su "giro pragmático"- que ese agente individual, manejándose de hecho mediante una función de utilidad como cualquier otro agente racional $^{84}$, debería procurar alcanzar, no obstante, un objetivo social (la maximización de la riqueza social o colectiva) cuyo contenido solo podría dirimirse conforme a los estándares estratégicos de la elección colectiva.

Como sostiene Olstrom, los "dilemas sociales" tienen lugar cuando un individuo, en situaciones de interacción, se enfrenta a elecciones en las cuales la maximización del auto-

\footnotetext{
80 Unites States vs. Carrol Towing Co., 159 United States F.2d Cir. 169 (1947).

${ }^{81}$ DWORKIN (1975) p. 1076.

82 Dworkin (1975) p. 1077. En cuanto a la distinción entre derechos abstractos y concretos, véase p. 1070.

83 Para una precisión de los supuestos egoístas de la racionalidad individual, véase Posner (2003a) p. 3.

${ }^{84}$ Posner (1993) pp. 3 y ss.
} 
interés en el corto plazo produciría resultados que dejarían a todos los participantes en una situación peor a cualquier otra alternativa ${ }^{85}$. Si a ello le añadimos el agravante de que no ha sido desarrollada, hasta el presente, una "teoría conductual de la elección colectiva" basada en modelos de racionalidad individual coherentes y consistentes con la evidencia disponible en torno a cómo esos individuos terminan tomando decisiones en situaciones de "dilemas sociales" (como sostiene Olstrom), resultaría inviable e injustificado, entonces, que los jueces puedan o deban resolver los "casos difíciles" aplicando directrices estratégicas como la que Posner y la mayoría de los analistas económicos sugieren.

\section{LA ECONOMÍA NEOCLÁSICA Y LOS REQUISITOS DE LA RACIONALIDAD PRÁCTICA}

Otra de las dificultades del análisis económico como teoría adjudicativa parece residir en el hecho de no poder ofrecer un enfoque normativo satisfactorio, es decir, un enfoque que tenga cierto "sentido jurídico" razonable desde la perspectiva del juez que debe decidir los "casos difíciles". En efecto, en el análisis económico de las decisiones judiciales yace una insuficiente distinción y armonización entre el plano descriptivo y el plano normativo de cualquier teoría sobre la acción humana (en este caso: una teoría de la acción adjudicativa), pues el analista económico no termina de asumir plenamente las diferencias existentes entre describir una acción y guiar una acción, como pondré brevemente de manifiesto en esta última sección.

MacCormick señala que el "razonamiento jurídico es un tipo especial, altamente institucionalizado y formalizado, del razonamiento moral" ${ }^{86}$. Conforme a ello, cualquier teoría plausible de la adjudicación debería poder justificar, de algún modo, el funcionamiento de las normas en un mundo que tenga "cierto sentido". Ahora bien, el tener "cierto sentido", cierta razonabilidad, no puede entenderse nunca -según el jurista escocés- en un sentido puramente descriptivo, pues las normas jurídicas "no describen el mundo con precisión ni fundan verdaderas predicciones"; ellas "no dan cuenta de, sino que establecen patrones de conducta"; no descubren las consecuencias de determinados efectos, sino que ordenan qué consecuencias se siguen de determinadas condiciones; en definitiva, "no presentan un modelo del mundo, sino un modelo para el mundo" ${ }^{87}$. Posner, por el contrario, al aplicar sin matices el enfoque espistemológico de la economía neoclásica a la teoría de la adjudicación, sostiene que "el aspecto más interesante y prometedor" del análisis económico del Derecho es, sin dudas, el enfoque positivo-descriptivo ${ }^{88}$, que permite realizar un buen número de predicciones en torno a lo que los jueces harán sobre la base de un modelo que, sin embargo, no pretende tener correlato alguno con la realidad ${ }^{89}$.

\footnotetext{
85 Olstrom (1998) p. 1.

86 MaCCORMick (1997) p. 272.

87 MacCormick (1997) pp. 103-104. Cursivas en el original.

88 Posner (1987b) p. 6.

89 Posner (2003a) p. 17.
} 
Existen cuatro órdenes distintos de la realidad imbricados en casi todos los estados de las cosas humanas con las que el Derecho tiene que ver ineludiblemente: un orden teórico o especulativo, un orden lógico, un orden práctico, y un orden técnico. Indudablemente la distinción que más le interesa al Derecho -y la que más problemática le resulta, a juzgar por las propias insuficiencias del AED- es la relativa al tercer y cuarto orden: la distinción entre el orden práctico y el orden técnico. Todo reduccionismo epistemológico en el ámbito de la filosofía práctica -el AED parece ser un ejemplo- busca de algún modo eludir las complejidades que supone la distinción y al mismo tiempo la referencia entre estos dos órdenes. Cualquier técnica jurídica: la técnica procesal, pericial o legislativa -incluso el Derecho mismo entendido como técnica- es claramente inteligible en cuanto mera técnica, por cierto, y toda técnica puede explicitarse a sí misma sin necesidad de abandonar el plano instrumental. Pero es indudable que tales técnicas se han originado y se sustentan en una elección moral, una elección que en cuanto decisión colectiva remite a la argumentación práctica y a los principios que la informan, principios de los que obtiene en última instancia su legitimidad. Entonces, difícilmente pueda justificarse una decisión cualquiera, es decir, difícilmente pueda explicitarse la razón por la que la voluntad individual o colectiva se inclina por una opción y no por otra si se recurre solo a argumentos técnicos y se permanece de manera indefinida en el plano de lo meramente instrumental o normatividad técnica. Pues como sostiene John Finnis, las elecciones moralmente significativas para el Derecho son "abiertas e inconmensurables", ya que los bienes implicados en esas elecciones (especialmente los bienes fundamentales para las personas humanas) no pueden ser "ponderados ni medidos en la forma en que lo exige la economía”, mediante un simple cómputo de costos y beneficios, o mediante cualquier otro método agregativo propuesto para guiar la elección" ${ }^{\prime 90}$.

La insuficiencia última del AED radicaría, entonces, en la circularidad de sus propios argumentos, pues la normatividad en la que se funda es, en definitiva, una mera normatividad técnica que nunca puede explicar el para qué del Derecho. La normatividad técnica del AED solo "explica" el cómo del Derecho, y esto, en verdad, tampoco lo hace demasiado bien, pues si el Derecho es visto solo "desde fuera" como una técnica compleja (el punto de vista del observador externo propio de las comprensiones positivistas de lo jurídico), difícilmente se pueda captar, entonces, su razonabilidad. Un análisis adecuado de esta razonabilidad exigiría un tratamiento más extenso que el brindado aquí. Pero me bastará señalar que la razonabilidad propia del orden práctico, como John Finnis sostiene, va más allá de las reglas imperantes en el orden lógico, y ciertamente no puede confundirse con la racionalidad instrumental que solo juzga la eficiencia de los medios (normatividad técnica) ${ }^{91}$. La razonabilidad del orden práctico está dada, principalmente, por la razonabilidad del fin que toda acción humana debe perseguir. Por ello, una adecuada integración entre el plano descriptivo y el plano normativo de la teoría jurídica solo podría lograrse desde una comprensión de los derechos que no los vea simplemente como "mercancías que se compran y se venden por un precio", sino como bienes humanos, bienes sobre los que se puede especular, ciertamente, pero que exigen ser ante todo realizados y concretizados (porque

\footnotetext{
90 Finnis (2011a) p. 243.

91 Para una adecuada distinción entre el orden práctico y el orden lógico, véase FinNis (1998) pp. 20 y ss.
} 
son fines), bienes que proporcionan razones tanto para una auténtica elección como para la acción, bienes que en definitiva dan completo sentido a los sentimientos y a las espontaneidades subyacentes en la naturaleza humana.

Pero entonces, la raíz de todas las insuficiencias del AED parecería residir en la misma dificultad de la economía neoclásica para comprender la dimensión y la naturaleza de la razón práctica, pues en última instancia debemos plantearnos seriamente si este enfoque de la economía en la que se funda el AED cumple con los requisitos esenciales de la racionalidad práctica.

Según el Profesor Ricardo Crespo, la teoría neoclásica hace radicar su presunto éxito -que consiste en resolver de un modo exacto la ecuación de maximización del uso de los medios- precisamente gracias a una "puesta entre paréntesis de la misma razón práctica"92. En efecto, Lionel Robbins -autor del Ensayo sobre la naturaleza y significación de la ciencia económica (1932) - definió claramente el planteo metodológico de la economía neoclásica como un método que prescinde de los fines y se ocupa solo de los medios. Dados unos fines supuestos, a los que solo se les pide que "se comporten bien" (well-behaved), es decir, que sean coherentes, la economía puede determinar el uso de los medios que conduce una conclusión exacta y óptima.

Sin embargo, la desventaja de esta operación de Robbins, según Crespo, radica en que si los fines se consideran "dados" (meros datos abstractos), la economía deja de ser entonces la ciencia de una acción humana real (pues no hay acción sin fines), y se repliega hacia el orden de lo meramente técnico. Paradójicamente, fue Robbins quien sostuvo que la economía se diferenciaba de la técnica en que la ciencia económica consideraba varios fines y la técnica uno solo ${ }^{93}$. Pero si la diferencia entre una mera técnica y la economía radica en la diferencia entre la unicidad y la multiplicidad de los fines (dando lugar a la libertad en el segundo caso), el hecho de considerar los fines como dados y abstractos terminará transformando su multiplicidad en unicidad, dando lugar así al llamado "mapa de preferencias" de la economía neoclásica. El mismo Robbins reduce los diversos fines de la conducta económica al único fin de la utilidad, con lo cual la economía se vuelve una mera técnica. En consecuencia, la racionalidad envuelta en el único tipo de acción humana que la economía neoclásica considera es una racionalidad instrumental, como sostiene Davis:

"La teoría [económica] de la elección trata de ser instrumentalmente racional. La racionalidad instrumental se define como la elección de las acciones que satisfacen mejor los fines u objetivos de un individuo sea como fuera que estos resulten caracterizados. La racionalidad instrumental es una racionalidad de los medios eficientes, y es per se completamente agnóstica acerca de la naturaleza de los fines que sirve" ${ }^{94}$.

\footnotetext{
92 Algunos de sus trabajos más importantes tendientes a mostrar esta limitación de la economía neoclásica son: Crespo (1996), Crespo (1998), y Crespo (2013).

93 Robbins (1951) pp. 60-62.

94 Davis (2003) p. 27.
} 
Los fines "dados" de Robbins dispensan a la ciencia económica de conocer su contenido concreto, y eso los torna remplazables según una relación que se manifiesta en una escala de valores dados en la que "el fin de los fines" es la maximización de la utilidad". De este modo, lo único relevante para un agente económico es maximizar distintas "unidades de fines" mediante la mejor combinación o uso de los medios. La fungibilidad de los fines dispensa a la economía de conocer su contenido concreto. Sin embargo, como señala Finnis, esto se opone a los requisitos esenciales de la racionalidad práctica, pues las elecciones moralmente significativas para el Derecho son "abiertas e inconmensurables", y dicha inconmensurabilidad requiere el recurso a una comparación prudencial que solo puede realizar la razón práctica ${ }^{96}$.

Como puede apreciarse, no parece haber lugar suficiente en la economía neoclásica para las operaciones de la razón práctica.

\section{REFLEXIÓN FINAL}

Tras haber expuesto todas las dificultades teóricas que enfrenta el AED para sentar las bases de una teoría de las decisiones judiciales o teoría de la adjudicación, es necesario concluir con una última pero no menos importante reflexión.

A pesar de todas las dificultades señaladas, el AED parece, sin embargo, haber calado en una fibra íntima de la teoría general del Derecho en la que dista mucho de haberse dicho la última palabra, y en la que precisamente el AED se presentaba como una promesa de solución en sus inicios. Dicha fibra la constituye, en efecto, el problema de las consecuencias sociales (no solo económicas) que acarrean las sentencias judiciales, sobre todo en los "casos difíciles", que bien pueden ser aquellos en los que no basta la lógica deductiva para resolver los problemas de interpretación, relevancia, prueba o calificación, como señala MacCormick, sino también y de manera más amplia aquellos casos en los que "la opinión pública -esclarecida o no- está dividida de tal manera en que no es posible tomar una decisión que pueda satisfacer a unos y a otros" ${ }^{\prime 97}$. El fallo del 28 de agosto de 2012 de la Tercera Sala de la Corte Suprema de Justicia de Chile en la causa signada con el Rol No 19602012, conocida como "Central y Puerto Castilla", podría tomarse como ejemplo. Este fallo, de enorme trascendencia para la vida de miles de chilenos, ha puesto en evidencia la necesidad de discutir, una vez más, el margen de discrecionalidad razonable dentro del cual los jueces se deben manejar en la tutela de las garantías constitucionales, atendiendo, entre otras razones que limiten su discrecionalidad, a las consecuencias económicas que sus sentencias traerían aparejadas en las vidas de los justiciables.

La pregunta decisiva que el AED parece haber instalado en el debate contemporáneo es, entonces, la de si las Cortes o Tribunales de Justicia (sobre todo los Supremos) pueden (o incluso deben) velar por las consecuencias de sus fallos y, en todo caso, por qué clase de consecuencias deben velar.

\footnotetext{
95 Robbins (1951) pp. 38, 50 y 57.

96 Finnis (2011a) p. 243.

97 Atienza (2005) p. 72.
} 
Como he puesto de manifiesto en este trabajo, una pregunta de esa naturaleza no debería olvidar, cualquiera sea la respuesta que se le dé, los roles institucionales consagrados en la Constitución de la República. Los jueces no son economistas, ni estrategas de políticas públicas, ni les corresponde a ellos velar por el desarrollo económico de un país. Cualquier agente de planificación económica (pero con mayor razón un juez cuya función es hacer justicia) solo podría manejarse con conjeturas en torno a las consecuencias que acarrearían sus decisiones sobre el bienestar general de la población en un caso concreto (caso que involucra, por definición, solo a dos partes). Es llamativa la forma en que una teoría eficiente de la adjudicación puede llegar a contradecir la esencia misma del Estado de Derecho, al querer imitar la lógica del mercado en un área en la parece imposible cualquier mímesis. Pero entonces, ¿’los jueces no pueden ni deben velar por las consecuencias de sus fallos?

Ciertamente pueden y deben. Pero en estricto rigor, las únicas consecuencias que los jueces podrían y deberían atender no parecen ser las consecuencias económicas sino las contempladas en lo que MacCormick llama una justificación de "segundo nivel" (por referencia al "primer nivel” de la lógica formalista deductiva). En una justificación de "segundo nivel" resulta ciertamente válido el empleo de argumentos "consecuencialistas", pero su empleo se halla limitado por los principios de universalidad, consistencia y coherencia. El principio de universalidad requiere que para justificar una decisión, $x$, en cualquier "caso difícil" debe encontrarse o formularse una premisa normativa general, $Y$, ligada a las condiciones $a, b$ y $c$, tal que cada vez que se verifiquen las condiciones $a, b$ y $c$ cualquier juez debería decidir $x$. El principio de consistencia requiere que una decisión, $x$, se base en premisas normativas que no entren en contradicción con reglas de Derecho válidamente establecidas. Finalmente, la coherencia debe ser a la vez normativa y fáctica. La coherencia normativa requiere que una decisión, $x$, pueda encuadrarse en una serie de valores o principios morales que, tomados en conjunto, puedan configurar una forma de vida satisfactoria, mientras que la coherencia narrativa exige un examen lógico de aquellas cuestiones de hecho que no cabe observar ni comprobar por la experiencia sensible ${ }^{98}$.

Un consecuencialismo de esta naturaleza seguirá orbitando necesariamente en torno a una teoría formalista del Derecho, como puede apreciarse, y por esa sencilla razón seguirá habiendo una brecha difícil de salvar entre él y el tipo de pragmatismo jurídico que Posner postula como síntesis integradora y a la vez superadora del AED. En efecto, para Posner el pragmatismo jurídico "no podrá constituir nunca un suplemento al formalismo ni a ninguna teoría positivista del Derecho" en la medida en que el Derecho está, en su opinión, "radicalmente indeterminado", y por esa razón las fuentes convencionales de la adjudicación no tienen en absoluto prioridad alguna sobre otras fuentes no jurídicas de información a las que los jueces deberían acudir -y de hecho acuden, según su criterio- para prever las "consecuencias verosímiles que se seguirían de decidir un caso de una manera o de otra" $"$.

98 MacCormick (1997) capítulos V, VI, VII y VIII; una síntesis en Atienza (2005) pp. 114-122.

99 Posner (2003b) p. 82. 


\section{BIBLIOGRAFÍA CITADA}

Alchian, Armen (1965): "Some Economics of Property Rights", Il Politico, no 30: pp. 816-829.

AleXY, Robert (1993): Teoría de los derechos fundamentales (Madrid, Centro de Estudios Constitucionales).

Atienza, Manuel (2005): Las razones del Derecho. Teorías de la argumentación jurídica (México, Instituto de Investigaciones Jurídicas, Universidad Autónoma de México, Serie Doctrina Jurídica no 134 ).

Becker, Gary (1976): The Economic Approach to Human Behaviour (Chicago, The University of Chicago Press).

Becker, Gary y Stigler, George (1977): "De Gustibus Non Est Disputandum”, American Economic Review, vol. 67, no 2: pp. 76-90.

Calabresi, Guido (1961): "Some Thoughts on Risk Distribution and the Law of Torts", Yale Law Journal, no 70: pp. 499-553.

Calabresi, Guido (1968): "Transaction Costs, Resource Allocation and Liability Rules. A Comment", The Journal of Law and Economics, vol. XI, pp. 67-73.

Coase, Ronald (1960): "The Problem of Social Cost", The Journal of Law and Economics, vol. 3: pp. 1-44.

COASE, Ronald (1978): "Economics and Contiguous Disciplines", The Journal of Legal Studies, vol. 7, no 2: pp. 201-211.

CoAse, Ronald (1998): “The New Institutional Economics", The American Economic Review, vol. 88, no 2: pp. 72-74.

Coleman, Jules L. (1984): "Economics and the Law: A Critical Review of the Foundations of the Economic Approach to Law", Ethics, vol. 94, no 4: pp. 649-679.

Crespo, Ricardo (1998): "The Notion of Economy and the Method of its Science According to Lionel Robbins", Journal of Indian Council of Philosophical Research, vol. $\mathrm{XV}, \mathrm{n}^{\circ}$ 2: pp. 33-44.

Crespo, Ricardo (2006): "Las racionalidades de la Economía”, Cuadernos de Empresa y Humanismo (Universidad de Navarra) n 96: pp. 1-88.

Crespo, Ricardo (2013): “Two Conceptions of Economics and Maximization”, Cambridge Journal of Economics, vol. 37: pp. 759-774.

D’Amato, Anthony (1992): "Post-Revolutionary Law and Economics: A Foreword to the Symposium", Hofstra Law Review, n 20: pp. 757-775.

DAvIs, John B. (2003): The Theory of Individual in Economics (London, Routledge).

Dworkin, Ronald (1975): "Hard Cases", Harvard Law Review, vol. 88, no 6: pp. 1057-1109.

Dworkin, Ronald (2002): Los derechos en serio (Barcelona, Editorial Ariel).

Ellickson, Robert C. (1989): “The Case for Coase and Against Coaseanism", Yale Law Journal, vol. 99: pp. 611-630.

Finnis, John (1997): “Commensuration and Public Reason”, en: CHAnG, Ruth (edit.): Incommensurability, Incomparability and Practical Reason (Cambridge, Harvard University Press): pp. 215-233.

FInNIS, John (1998): Aquinas. Moral, Political, and Legal Theory (Oxford, Oxford University Press). 
FinNis, John (2000): Ley natural y derechos naturales (trad. de Cristóbal OrRego, Buenos Aires, Abeledo-Perrot, primera edición).

Finnis, John (2011a): "Economics, Justice, and the Value of Life", en: Finnis, John, Human Rights \& Common Good. Collected Essays. Vol. III (Oxford, Oxford University Press) pp. 242-250.

Finnis, John (2011b): "Adjudication and Legal Change”, en: Finnis, John, Philosophy of Law. Collected Essays. Vol. IV (Oxford, Oxford University Press) pp. 397-403.

FISS, Owen (1986): “The Death of the Law?", Cornell Law Review, vol. 72, no 1: pp. 1-16.

Garoupa, Nino (2011): "The Law and Economics of Legal Parochialism", University of Illinois Law Review, vol. 2011: pp. 1517-1529.

Guilford, Joy Paul (1954): Psycometric Methods (New York, McGraw-Hill).

HACKNEY Jr., James R. (2003): "Law and neoclassical economics theory: a critical history of the distribution/efficiency debate", Journal of Socio-Economics, vol. 32: pp. 361-390.

Hart, Herbert (1998): El concepto de Derecho (Trad. de Genaro Carrió, Buenos Aires, Abeledo-Perrot, primera edición).

Hicks, J. R. (1939): "The Foundations of Welfare Economics", The Economic Journal, vol. 49, n 196: pp. 696-712.

Jevons, William Stanley (1965): The Theory of Political Economy (New York, Sentry Press).

Jolls, Christine y Sunstein, Cass y Thaler, Richard (1998): "A Behavioral Approach to Law and Economics", Stanford Law Review, vol. 50, no 5: pp. 1471-1550.

Kaldor, Nicholas (1939): "Welfare Propositions of Economics and Interpersonal Comparisons of Utility”, The Economic Journal, vol. 49, n 195: pp. 549-552.

LeIter, Brian (2011): Naturalizing Jurisprudence. Essays on American Legal Realism and Naturalism in Legal Philosophy (Oxford, Oxford University Press).

Llewellyn, Karl (1930): “A Realistic Jurisprudence. The Next Step”, Columbia Law Review, vol. 30, no 4: pp. 431-465.

Lynn Spencer, Deborah (1998): History and Discourse in Law and Economics: 1920-1985 (Indiana, Department of Economics, University of Notre Dame).

MacCormick, Neil (1997): Legal Reasoning and Legal Theory (Oxford, Clarendon Press).

MACKAAY, Ejan (2000): "History of Law and Economics", en: AA.VV., Encyclopedia of Law And Economics, vol. 1 (Cheltenham, Edward Elgar Publishing) pp. 65-117.

Martínez Cinca, Carlos Diego (2009): "Maximización de la riqueza y asignación de derechos en Richard Posner”, Persona y Derecho, vol. 60: pp. 323-351.

Martínez Cinca, Carlos Diego (2010): La justicia como recurso económico: un análisis crítico del Análisis Económico del Derecho (Mendoza, Facultad de Filosofía y Letras, Universidad Nacional de Cuyo).

Martínez Cinca, Carlos Diego (2012): "Límites del análisis económico como teoría interpretativa y argumentativa del Derecho", en: Cianciardo Ortega, Juan (Coord.): Constitución, Neoconstitucionalismo y Derechos (México, Porrúa) pp. 29-63.

Martínez Cinca, Carlos Diego (2013): “¿Son eficientes las decisiones de los jueces norteamericanos en los "casos difíciles"? Las vacías respuestas del Análisis Económico del Derecho", Revista de Derecho Público Iberoamericano, no 2: pp. 35-66. 
Martínez Cinca, Carlos Diego y Crespo, Ricardo F. (2013): "El revisionismo austríaco y la concepción aristotélica del valor. Sesgos y claves para una nueva revisión”, Anales del Seminario de Historia de la Filosofía, vol. 30, no 1: pp. 11-26.

Massini Correas, Carlos Ignacio (2005): Filosofía del Derecho. Tomo II: La justicia (Buenos Aires, Abeledo-Perrot).

Medema, Steven G. (1999): "Legal Fiction: The Place of the Coase Theorem in Law and Economics", Economics and Philosophy, vol. 15: pp. 209-233.

Mercado Pacheco, Pedro (1994): El Análisis Económico del Derecho. Una reconstrucción teórica (Madrid, Centro de Estudios Constitucionales, no 38 de la Colección "Derecho y Justicia”).

Mercuro, Nicholas y Medema, Steven (2006): Economics and the Law. From Posner to PostModernism and Beyond (New Jersey, Princeton University Press).

Mery Nieto, Rafael (2004): "Notas sobre Análisis Económico del Derecho: Una mirada desde América Latina", Revista Derecho y Humanidades, no 10: pp. 121-140.

Meyerhof Salama, Bruno (2012): "A História do Declínio e Queda do Eficientismo na Obra de Richard Posner", Revista do Instituto do Direito Brasileiro, Ano 1, n o1: pp. 435-483.

Miquel, Juan Luis (1986): Resolución de los contratos por incumplimiento (Buenos Aires, Depalma).

Mishan, E. J. (1967): "Pareto Optimality and the Law", Oxford Economic Papers, vol. 19, no 3: pp. 255-287.

Olstrom, Elinor (1998): "A Behavioral Approach to the Rational Choice Theory of Collective Action", The American Political Science Review, vol. 92, no 1: pp. 1-22.efeirb197

Parisi, Francesco y Rowley, Charles (2005): The Origins of Law and Economics. Essays by the Founding Fathers (Cheltenham, Edward Elgar Publishing).

Posner, Richard (1973): "An Economic Approach to Legal Procedure and Judicial Administration”, Journal of Legal Studies, vol. 2, n² 2: pp. 399-458.

Posner, Richard (1975): "Economic Approach to Law", Texas Law Review, n 53: pp. 757-782.

Posner, Richard (1979): "Utilitarianism, Economics, and Legal Theory”, Journal of Legal Studies, vol. 8, no 1: pp. 103-140.

Posner, Richard (1980a): "Ethical and Political Basis of Efficiency Norm in Common Law Adjudication", Hofstra Law Review, n 8: pp. 487-507.

Posner, Richard (1980b): "A Reply to Some Recent Criticisms of Efficiency Theory of the Common Law", Hofstra Law Review, n 9, pp. 775-794.

Posner, Richard (1987a): "The Decline of Law as an Autonomous Discipline: 19621987”, Harvard Law Review, vol. 100: pp. 761-780.

Posner, Richard (1987b): "The Law and Economics Movement", American Economic Review Papers and Proceedings, $n^{\circ} 77-1$ : pp. 1-7.

Posner, Richard (1988): “The Jurisprudence of Skepticism”, Michigan Law Review, vol. 86, no 5: pp. 827-891.

Posner, Richard (1992): "The Strangest Attack Yet on Law and Economics", Hofstra Law Review, vol. 20: pp. 933-940.

Posner, Richard (1993): "What Do Judges and Justices Maximize? (The Same Thing Everybody Else Does)", Supreme Court Economic Review, vol. 3: pp. 1-41. 
Posner, Richard (1996): "Wealth Maximization and Tort Law: A Philosophical Inquiry", en: Owen, David G. (ed.), Philosophical Foundations of Tort Law (Clarendon, Oxford University Press) pp. 99-112.

Posner, Richard (71998): The Economics of Justice (Cambridge, Harvard University Press).

Posner, Richard (1999): The Problems of Jurisprudence (Cambridge, Harvard University Press).

Posner, Richard (2003a): Economic Analysis of Law (New York, Aspen Publishers, sexta edición).

Posner, Richard (2003b): Law, Pragmatism, and Democracy (Cambridge, Harvard University Press).

Posner, Richard (2010a): The Quotable Judge Posner. Selections from Twenty-Five Years of Judicial Opinions (Edited \& with an Introduction by Robert F. BLOMQUIST, New York, State University of New York Press).

Posner, Richard (2010b): How Judges Think (Cambridge, Harvard University Press).

Raz, Joseph (2009): Between Authority and Interpretation. On the Theory of Law and Practical Reason (Oxford, Oxford University Press).

Robbins, Lionel (1951): Ensayo sobre la naturaleza y significación de la ciencia económica (Fondo de Cultura Económica, México).

SEN, Amartya (1970): “The Impossibility of a Paretian Liberal”, Journal of Political Economy, vol. 78, n 1: pp. 152-157.

Sen, Amartya (2004): On Ethics and Economics (Oxford, Blackwell Publishing).

SHAPIRO, Ian (2005): The Flight from Reality in the Human Sciences (New Jersey, Princeton University Press).

Suppes, Patrick (2000): “Measurement, Theory of", en: GraIG, Edward, Concise Routledge Encyclopedia of Philosophy (London, Routledge) pp. 549-550.

Yowell, Paul (2012): "Legislación, Common Law, y la virtud de la claridad", Revista Chilena de Derecho, vol. 39, no 2: pp. 481-512. 
